\title{
Transformando O PATRIARCADO? \\ O PAPEL DA LUTA FEMINISTA NA RECONFIGURAÇÃO DAS \\ CATEGORIAS MARXISTAS
}

Marta Nunes da Costa ${ }^{1}$

Resumo: A partir de uma análise de categorias marxistas, neste artigo, quero trazer para o domínio da visibilidade a "questáo da mulher" e defender que esta deve ser o fio condutor no processo de identificação (ou invenção) de condiçōes de possibilidade para a transformação do sistema das práticas (e discursos) que visam à emancipaçâo humana, entendida como superação da lógica de dominação.

Palavras-Chave: Patriarcado. Capitalismo. Feminismo. Esquerda. Gênero.

Qual a relação entre patriarcado e capitalismo? De que forma a luta feminista oferece condiçóes para transformação (e superação) dessa relação? Quero, neste artigo, tentar responder a essas questóes. A exposição passa por três momentos. Num primeiro momento, a partir de uma análise de textos de Marx e Engels, olho para a forma como os autores refletem acerca da divisáo dos sexos e seus desdobramentos na divisão social do trabalho. No segundo momento, a partir de um diálogo com Roswitha Scholz, exploro a relação entre trabalho abstrato e princípio masculino, mostrando como, em função

${ }_{1}^{1}$ Professora Adjunta de Filosofia na Universidade Federal do Mato Grosso do Sul, Campo Grande, MS - Brasil. E-mail: nunesdacosta77@gmail.com

Professora Permanente do Programa de Pós-Graduação de Filosofia da UNIOESTE. Coordenadora do Grupo de Estudos Democráticos (CNPq - www.estudosdemocraticos.com.br). Doutorada em Ciência Política pela New School for Social Research, Nova Iorque, NY, EUA (2006). Publicou recentemente três livros: Razôes, paixóes, utopias: democracia em questáo (São Paulo: LiberArs, 2018); Ensaios no feminino (São Paulo: LiberArs, 2018), Os dilemas de Rousseau (Ijuí: Unijuí, 2017). Autora de vários artigos em diferentes revistas: Debate Feminista; Theoria - A Journal of Social and Political Theory; Veritas; Ethica, entre outras.

http://dx.doi.org/10.1590/0101-3173.2018.v41n3.07.p125 
dessa identificação, se relega o feminino para uma esfera privada, que passa progressivamente a representar o oposto da esfera pública (definida pelo trabalho do "homem"). Porém, enquanto Scholz preconiza que a cisão entre privado/público, feminino/masculino constitui uma relação de interdependência, defendo aqui que é impossível considerar tal relação como relação de reciprocidade; pelo contrário, a relação entre homem/mulher manifesta a assimetria de relaçôes de poder intrínsecas a uma lógica de dominação do patriarcado. No terceiro momento, sustento que a universalização do "trabalho abstrato" e sua extensão às mulheres obrigam-nos hoje a desenvolver uma crítica acerca da "questão da mulher" e seu papel na superação ou transformação do patriarcado. Essa crítica parte de três deslocamentos importantes: 1. O deslocamento da lógica de conflito de classes para a lógica do gênero; 2 . O deslocamento da razão abstrata instrumental para uma razão sensivel; 3. O deslocamento de uma esquerda "abstrata" e ossificada para uma esquerda feminista, consciente da dupla cisão estrutural e pessoal constitutiva de todas as relaçóes sociais. Com base em tal crítica, é possível não só transformar o esquema conceitual através do qual se analisa e se atribui, projetando, um sentido à realidade, como também transformar as práticas atuais - reguladas pelo fetichismo da mercadoria -, subvertendo as suas intençóes originais.

\section{MARX E A AUSÊNCIA DAS MULHERES - O QUE NOS REVELA O NÃO-DITO}

Pode ser visto como parte de uma crítica recorrente dizer que Marx é cego à questão do gênero ou que, por outras palavras, Marx é culpado (pelo menos parcialmente) de uma lógica sexista, a qual, por ser propositadamente cega aos desdobramentos trazidos pela diferença de gênero e sua relação com o trabalho abstrato, acaba contribuindo para obscurecer mais do que revelar ou denunciar o carácter específico do capitalismo.

Muitas críticas têm sido feitas a Marx e Engels; Di Stefano, por exemplo, identifica nos autores uma visão sobretudo masculinizada na forma como tratam a relação entre natureza e cultura e como concebem a emancipação (a partir de uma superaçáo do domínio da necessidade). Como afirma a autora,

[t]odas as suas reivindicaçóes de emancipação e liberação, esta visão de uma humanidade sem limites repousa numa imagem espelhada que é sinistra na qual as mulheres, a natureza e a necessidade estão ligadas e contra a qual os homens modernos têm de testar incessantemente as suas capacidades e limites. (DI STEFANO, 1991, p. 127). 
Ou seja, para Di Stefano, Marx e Engels visam transformar a sociedade com a superação das dicotomias, mas não o conseguem fazer, já que se movem num horizonte simbólico definido pela oposição mulher/natureza/necessidade e homem/sociedade/liberdade. Esse dualismo, de acordo com Di Stefano, torna-se insuperável, porque Marx não leva às últimas consequências uma crítica que desvele e possibilite o reconhecimento da importância do trabalho das mulheres (e da dependência das crianças e dos homens, face às mulheres). Outras autoras, como Holmstrom (1984), por exemplo, consideram que o silêncio de Marx acerca das mulheres não é necessariamente problemático, especialmente porque é impossível encontrar uma conceitualização essencialista de natureza humana; tendo em conta que a nossa natureza se transforma consoante as condiçóes sociais e produtivas, a "natureza" das mulheres está também sujeita à mudança, e essa mudança começa pelo próprio trabalho.

Seja por que ângulo abordemos a questão, nenhuma crítica parece inteiramente justa ou sequer completa, i.e., capaz de identificar, de forma clara, os pontos em que Marx e Engels caracterizaram com rigor, sem serem eles mesmos vítimas de uma ideologia dominante (inclusive a sua própria), a questấo e problema do gênero, sua relação e seu papel no sistema capitalista, quer como condição de reprodução do sistema (via trabalho), quer como condição de resistência e superação do capitalismo, e, nesse sentido, como locus possivelmente privilegiado de emancipação humana (e não apenas das mulheres). Com efeito, apesar de Marx, em $O$ capital, se esquivar dessa problematização do gênero, preferindo concentrar-se sobre o trabalho abstrato e a "média" do trabalhador, podemos identificar, nos textos de Marx e Engels (lembrando que os autores têm posiçóes que não são necessariamente compatíveis acerca dessa questão), alguma resistência à adoção cega dessa lógica sexista (ou ideologia vitoriana), até porque, caso não o fizessem, a sua crítica teria sido apenas parcial, incompleta e, portanto, insuficiente para qualquer tipo de transformação. É impossível considerar a questáo de gênero como secundária ao problema e especificidade do capitalismo.

No Manifesto comunista, por exemplo, Marx e Engels denunciam a maneira pela qual a burguesia constrói todas as relaçóes sociais (sobre o capital). Eles enfatizam:

Sobre que fundamento repousa a família atual, a família burguesa? Sobre o capital, sobre o ganho individual. A família, na sua plenitude, só existe para a burguesia, mas encontra seu complemento na ausência forçada da 
família entre os proletários e na prostituição pública. [...] O palavreado burguês sobre a família e a educação, sobre os doces laços que unem a criança aos pais, torna-se cada vez mais repugnante à medida que a grande indústria destrói todos os laços familiares dos proletários e transforma suas crianças em simples artigos de comércio, em simples instrumentos de trabalho. (MARX.; ENGELS, 2005, p. 55).

Logo de seguida, vem uma passagem específica sobre as mulheres:

Para o burguês, a mulher nada mais é do que um instrumento de produção. Ouvindo dizer que os instrumentos de produção serão explorados em comum, conclui naturalmente que o destino de propriedade coletiva caberá igualmente às mulheres. Não imagina que se trata precisamente de arrancar a mulher de seu papel de simples instrumento de produção. (MARX.; ENGELS, 2005, p. 55-56).

Essas duas passagens de texto permitem-nos tirar algumas ilaçóes: em primeiro lugar, que a dificuldade dos autores em tratar a questão do gênero pode ser lida à luz da constelação específica que ambos descrevem, ou seja, a ausência das mulheres se deve não a uma escolha consciente feita pelos autores no "tema" ou "sujeito" que se torna protagonista da sua reflexão, descrição e crítica, mas, antes, essa ausência retrata e reflete o espaço (invisível) que as mulheres foram forçadas a ocupar (i.e., na esfera privada da "casa" e na transformação da "família patriarcal" em "família" burguesa). Apesar disso, podemos afirmar que a teoria de Marx e Engels é suficientemente flexível para incluir a questão das mulheres, quando mais não seja, pelo viés de crítica da economia política. Em segundo lugar, poderíamos ir mais longe e afirmar que a crítica ao papel a que as mulheres estão delimitadas possibilita vê-las não apenas como exemplo da opressão da lógica burguesa e capitalista, mas como elemento crucial na constituição e (possível) sucesso de um movimento de resistência ao capitalismo. Homens e mulheres devem recriar uma base a partir da qual possam trabalhar juntos e projetar o que desejam ser, numa sociedade futura, onde as relações sociais não são "naturais" nem estão pré-determinadas. A opressão das mulheres é uma de entre muitas outras formas de opressão capitalista; porém, ela é também a mais fundamental, aquela que nos obriga a questionar o estatuto (mesmo que apenas conceitual) da "natureza humana", do "progresso" e, inclusive, da transformação social.

De acordo com Marx, o conceito de alienação é um conceito-chave para se compreender a estrutura e organização da sociedade moderna. Os $\mathrm{Ma}$ - 
nuscritos econômico-filosóficos de 1844 são o texto por excelência onde podemos encontrar os desdobramentos conceptuais da "alienação". Aquilo que começa por ser o fator distintivo entre seres humanos e animais, a saber, o trabalho na sua forma criativa, perde a sua especificidade no modo de produção capitalista e deixa de ser um processo fundamental de afirmação da própria vida, tornando-se o seu oposto. $\mathrm{O}$ trabalho se torna espaço de produção e perpetuação de alienação. Essa alienação não é apenas a perda de controle ou de relação essencial com o objeto (de trabalho) produzido, mas também a perda de relação com o meio de produção e com os outros seres humanos. A separação e o estranhamento nos quais o sujeito é lançado fomentam o distanciamento e o abismo radicado na própria subjetividade e na comunidade com os outros sujeitos, na criação de um mundo comum como expressão de um ser-espécie. $\mathrm{O}$ sujeito que se aliena devido à particularidade do modo de produção capitalista vai ser transformado - de sujeito humano (criador e livre) em sujeito que se reduz forçosamente às suas necessidades animais, físicas, mutilando o potencial para a sua humanidade. Isso significa que a alienação não afeta somente o sujeito alienado, todavia, toda a estrutura e rede geral de relaçóes sociais, ou seja, "[a] alienação existe não apenas no local de trabalho, mas se estende a todas as relações sociais. Isto é particularmente importante para compreender as relaçôes de gênero." (BROWN, 2012, p. 37).

Homens e mulheres se constituem como tal a partir de circunstâncias específicas, mediadas por relaçóes sociais definidas. No texto $A$ ideologia ale$m a \tilde{a}$, Marx e Engels discutem a origem da família e da sociedade de classes. Aqui, o homem passa a distinguir-se do animal desde o momento em que a consciência "toma o lugar do instinto ou de que seu instinto é um instinto consciente. Essa consciência gregária ou tribal se desenvolve e se aperfeiçoa posteriormente em razão do aumento da produtividade, do aumento das necessidades e do crescimento populacional.” (MARX; ENGELS, 2001, p. 26). É através desse desenvolvimento da consciência, que, semelhante à descrição feita por Rousseau, no Segundo discurso, introduz a distinção entre sujeito e natureza, na medida em que o sujeito passa a se ver como separado do mundo, que está também na base da divisão do trabalho. Na continuação dessa mesma passagem, os autores ressaltam:

Assim se desenvolve a divisão do trabalho que outra coisa não era, primitivamente, senão a divisão do trabalho no ato sexual, e depois se tornou a divisão de trabalho que se faz por si só ou "pela natureza" em virtude das disposiçóes naturais (vigor corporal, por exemplo), das necessidades, do acaso, etc. A divisão do trabalho só se torna efetivamente divisão do tra- 
balho a partir do momento em que se opera uma divisão entre o trabalho material e o trabalho intelectual. A partir desse momento a consciência pode de fato imaginar que é algo mais do que a consciência da prática existente, que ela representa realmente algo, sem representar algo real. (MARX; ENGELS, 2001, p. 26).

A partir desse momento, geram-se condições para produção de teorias que entram em contradição com as relaçôes existentes; contudo, essas contradiçóes só existem porque refletem contradiçóes anteriores, a saber, a contradição entre as relações sociais e a força produtiva. A divisão do trabalho é problemática, porque, ao mesmo tempo em que reflete essas contradições, ela assenta sobre uma "divisão natural do trabalho na família e na separação da sociedade em famílias isoladas e opostas umas às outras." (MARX; ENGELS, 2001, p. 27). Mas até que ponto essa divisão é "natural"? Como devemos entender o sentido de "natural”, nessa passagem? Marx e Engels (2001, p. 27-28) afirmam que, afinal,

[essa] divisão do trabalho encerra ao mesmo tempo a repartição do trabalho e de seus produtos, distribuição desigual na verdade, tanto em quantidade quanto em qualidade. Encerra, portanto, a propriedade, cuja primeira forma, o seu germe, reside na família onde a mulher e os filhos são escravos do homem. A escravidão, certamente ainda muito rudimentar e latente na família, é a primeira propriedade, que aliás já corresponde perfeitamente aqui à definição dos economistas modernos segundo a qual ela é a livre disposição da força de trabalho de outrem. Assim, divisão do trabalho e propriedade privada são expressóes idênticas - na primeira se enuncia, em relação à atividade, aquilo que na segunda é enunciado em relação ao produto dessa atividade.

Essa passagem tem sido problematizada por várias teoristas feministas. Em primeiro lugar, Marx e Engels parecem, de fato, asseverar que a primeira divisão do trabalho (a da procriação) é "natural", enquanto a segunda divisão do trabalho (i.e., a divisão entre trabalho intelectual e manual) é vista como a primeira divisão social do trabalho. Isso é problemático, na medida em que, ao considerar apenas a segunda divisão como social, os autores contribuem para um discurso do determinismo biológico que está na base da naturalização da desigualdade entre homens e mulheres. Essa é a crítica de Mies, que desvela a ambiguidade do texto e problematiza a sobreposição das ordens biológica e social (MIES, 1998). Quão natural é a escravidão das mulheres e o seu estatuto de "propriedade" dos homens? Se os seres humanos são iguais, não tanto 
por natureza mas por direito adquirido e construído a partir da (re)invenção de si mesmos, enquanto agentes históricos e políticos conscientes, isso significa que, tal como Rousseau nos ensinou, qualquer desigualdade estabelecida e naturalizada tem que ser necessariamente ilegítima, i.e., sem fundamentos. ${ }^{2}$ Encontramos aqui uma das tensóes explícitas no pensamento de Marx: ao mesmo tempo em que parece recusar uma leitura essencialista da natureza humana (já que isso o levaria a um beco conceitual e prático), ele é vítima da sua própria crítica, pois parte dessa desigualdade entre homens e mulheres como sendo, de alguma forma, justificada pela natureza física e biológica.

É, sem dúvida, um desafio tentar compreender e atribuir sentido à forma como feminismo e marxismo podem andar juntos. $\mathrm{O}$ nosso ponto de partida é a desigualdade nas relaçóes sociais, no âmbito da família; entretanto, mesmo essa "família" não pode ser universalizada, porque, como a passagem acima citada demonstra, só os burgueses se dão o luxo de ter "famílias", enquanto os proletários são extirpados do hipotético direito de as ter, pois, quer as mulheres, quer as crianças são vistas apenas como instrumentos de trabalho, instrumentos desiguais, quando comparados aos homens. A secçáo acerca da acumulação primitiva de $O$ capital mostra como o processo violento de expropriação e "despossessão" ${ }^{3}$ e roubo, o qual culmina na concentração dos meios de produção nas mãos de alguns e transforma a propriedade coletiva na propriedade privada, é um processo e prática normal dentro do sistema capitalista. ${ }^{4}$ Mais do que isso, esse processo de acumulação primitiva é a condição para que a relaçáo capitalista possa ser criada, já que esta

não pode ser senão o processo de separação entre o trabalhador e a propriedade das condiçóes de realização de seu trabalho, processo que, por um lado, transforma em capital os meios sociais de subsistência e de produçáo e, por outro lado, converte os produtores direitos em trabalhadores assalariados. A assim chamada acumulação primitiva náo é, por conseguinte, mais do que o processo histórico de separaçáo entre produtor e meio de produção. Ela aparece como "primitiva" porque constituir a pré-história do capital e do modo de produção que lhe corresponde. (MARX, 2015, p. 961).

\footnotetext{
2 Ver o Segundo discurso sobre a origem e fundamento da desigualdade entre os homens, onde Rousseau apresenta o diagnóstico, via crítica, da condição presente, e ver igualmente $O$ Contrato Social, onde o autor expóe um programa positivo de transformação política, social e simbólica.

${ }^{3}$ Aqui uso o termo de David Harvey (2011).

${ }^{4}$ Marx (2015, p. 161) afirma: "Na história real, como se sabe, o papel principal é desempenhado pela conquista, a subjugação, o assassínio para roubar, em suma, a violência. [...] os métodos da acumulação primitiva podem ser qualquer coisa, menos idílicos."
} 
A nudez a que os proletários são condenados, isto é, a condição a que eles se submetem, agora despidos de propriedade, de terra ou de qualquer relação mais substancial e necessária com a natureza, obriga a que estes sejam atirados para uma luta desenfreada pela sobrevivência, sujeitando-se a vender a sua capacidade de trabalho pelo que os burgueses estiverem dispostos a pagar.

É interessante notar que toda a descrição feita nesse capítulo exclui qualquer referência às mulheres; mas esse processo de expropriação e proletarização dos trabalhadores, convertendo as suas condiçôes de trabalho em capital, só é possível na medida em que as mulheres permitam que assim seja: ou seja, as mulheres invisiveis são a condição necessária para que o processo de exploração seja viável, porque, sem elas e tudo o que elas proporcionam (o trabalho não pago que faz com que o homem proletário possa ser assalariado de outrem), o modo de apropriação capitalista ficaria comprometido. Podemos sustentar que o sistema capitalista instrumentaliza o fato de ser mulher de forma a tirar vantagem das diferenças sociais e históricas entre os gêneros. Com efeito, a própria teorização marxista se constrói sobre dicotomias instrumentais que se naturalizam e passam a constituir-se e representar-se como "imaginário coletivo", como narrativa subjacente à definição e compreensão do sistema capitalista, nas suas diferentes fases. ${ }^{5}$

\section{A MASCULINIZAÇÁO DO TRABALHO ABSTRATO - CAPITALISMO E A IMPOSSIBILIDADE DA RECIPROCIDADE}

Neste momento, através de um diálogo com Roswitha Scholz, quero explorar a relação entre trabalho abstrato e princípio masculino, mostrando como, a partir dessa identificação, se relega o feminino para uma esfera privada, a qual passa progressivamente a representar o oposto da esfera pública (definida pelo trabalho do "homem"). A cisão entre privado/público, feminino/masculino constitui simultaneamente uma relaçáo de interdependência, embora, ao contrário do que Scholz defende, não a veja como relação de reciprocidade, mas, antes, a explicitação da assimetria de relaçóes de poder e a progressiva afirmação de uma lógica de dominação explicitada no patriarcado.

\footnotetext{
5 Porém, não devemos negligenciar as diferenças existentes entre as mulheres, consoante à constelaçáo a que pertençam (seja rica/burguesa ou pobre/proletária, mas se deveria aqui também incluir a questão de raça na reflexão sobre o gênero).
} 
A teoria de Marx e Engels assenta no pressuposto de que as ideias dominantes de cada época são produzidas pelos detentores dos meios de produção dessa época, ou seja, as condiçôes materiais determinam os conteúdos intelectuais. Aprendemos com o capítulo sobre a acumulação primitiva do capital que o processo pelo qual os indivíduos se tornam proletários corresponde simultaneamente ao processo em que eles perdem toda e qualquer referência, proteção ou direito sobre a terra, o que significa que os proletários passam a existir enquanto tal devido à ruptura do paradigma do feudalismo. Esse paradigma é quebrado desde o movimento da Reforma, no século XVI, e invenção do Estado-moderno, com todas as usurpaçóes de propriedades da Igreja e progressiva transformação social, refletida na invenção ou emergência de novas camadas (como os vagabundos ou escravos). Por outro lado, esses proletários, ao mesmo tempo em que se tornam desiguais pela ausência de poder que têm sobre a terra (e seus meios de produção), são projetados e postulados como detentores de uma "igualdade" conferida pelo direito de entrar em relaçóes contratuais - isto é, de vender a sua força de trabalho em troca de um salário. Isso é o que aparece, o que é tornado visível, a saber, a contradição entre o discurso da igualdade assente na defesa de uma nova ideologia que se tornará dominante (de que todos temos "direitos") e a prática estabelecida da desigualdade que gera o aumento do abismo entre aqueles que nada têm e só se podem vender a si mesmos, e aqueles que tudo têm e ditam as ideias e práticas de uma época. No entanto, isso que aparece assenta em relaçóes existentes, mas tornadas invisíveis, do ponto de vista da nova ideologia que promove a separaçáo entre esfera pública e esfera privada. As mulheres, as quais haviam sido distinguidas dos homens pela divisão sexual, tornam-se invisíveis na divisão social do trabalho, porque são condenadas a uma esfera "do lar" que é desigual, i.e., que não tem igual estatuto nem pode reivindicar o mesmo direito a aparecer em público. Roswitha Scholz sublinha o conjunto de implicaçóes dessa distinção (que ela não teoriza dessa forma, mas que permite essa leitura), e que, nas suas palavras, se traduz na distinção entre o princípio masculino e a "esfera feminina".

O discurso de Marx, pelo menos em $O$ capital, parece ser vítima de algo que é comum entre os modernos: a desconsideraçáo pelo gênero é necessária e propositada (mesmo que de forma inconsciente), pois só assim é possível manter e promover um discurso que reivindique validade universal (assente na razão). Também o discurso que procura compreender e desvelar as dinâmicas do capital assenta num princípio que parece sexualmente neutro, isto é, na categoria do trabalho e do trabalho abstrato. Esse discurso reclama aplicabilidade 
universal, ou seja, reivindica ser válido para todos os agentes que o encarnam, sejam estes homens ou mulheres. Porém, essa universalização repousa na adoção do patriarcado como grelha conceitual a partir da qual se orientam e definem as relaçóes sociais (que se traduzem nas relaçóes produtivas). Como afirma Scholz (1996, p. 17),

o conceito de patriarcado (e, com ele, o carácter de dominação da relação entre os sexos na forma-valor) é em parte evitado ou mesmo conscientemente negado através do recurso ao carácter fetichista da sociedade mercantil. [...] O problema pode ser aguçado pela seguinte alternativa: ou bem o trabalho abstrato e o valor são compreendidos já em seu nexo constitutivo (e, portanto, em seu próprio núcleo) como princípio masculino, ou bem se volta a uma hierarquia conceitual, em que a distribuição dos papéis sexuais é remetida, como simples "problema derivado" ou de "concretização" a uma correlação secundária.

Entendemos por patriarcado a internalização e naturalização de normas que expressam a dominação dos homens sobre as mulheres, isto é, o reconhecimento dos papéis que cada um deve desempenhar, de forma a ter aprovação pela coletividade. De acordo com a leitura de Scholz, aqui endossada, a dominação deve ser concebida como "sem sujeito", visto que traduz a grelha de parâmetros socioculturais que permitem a produção de subjetividades conforme esses mesmos parâmetros. Em outras palavras, essa dominação é simultaneamente internalizada, mas exterior aos sujeitos que por ela são definidos e constituídos, o que sugere a natureza dialética dessa construção e, sendo dialética, pressupóe a possibilidade de sua transformação. Por exemplo, demonstrámos anteriormente que a assimetria da relação entre trabalho abstrato (princípio masculino) e "feminino" se constrói a partir de um horizonte definido essencialmente pelas mulheres, já que só estas produzem a vida. Porém, a dominação se constrói a partir da projeção de que as mulheres se definem enquanto mulheres necessariamente no domínio do lar: "Cabia à mulher não apenas ser uma dona-de-casa exemplar, mas também tornar agradável a vida do marido com sua assistência, seus cuidados e seu interesse." (SCHOLZ, 1996, p. 25). No século XIX, altura da crítica feita por Marx e Engels, a "vocação materna" da mulher burguesa estava totalmente internalizada, acentuando o abismo entre a esfera pública e privada:

Casamento e maternidade se tornaram entấo o único locus social onde a mulher (burguesa) podia locomover-se; de resto, ela dependia inteiramente de seu marido. A domesticaçáo da mulher atingiu no século XIX um tal ápice que mesmo o forte instinto sexual imputado às mulheres ao longo 
do tempo chegou a ser desmentido. [...] A domesticação, portanto, foi infletida como tendência a um ser absolutamente assexuado. (cf. FREVERT, 1989, p.128ss). (SCHOLZ, 1996, p. 26).

Curiosamente, como mostra Scholz, é nessa mesma época que se dá o primeiro movimento feminista, reação parcial da Revolução Francesa. Esse movimento reivindicava sobretudo a "independência e maioridade no Estado", o acesso ao estudo e o direito à atividade remunerada, embora essa atividade estivesse circunscrita a esferas específicas, como o comércio, o ensino e, posteriormente, a assistência social. (SCHOLZ, 1996, p. 27). Mesmo a luta por remuneração digna do trabalho era feita tendo como horizonte a aceitação de que a mulher tinha determinadas "vocações naturais"; além disso, tais reivindicaçôes se davam num contexto definido por luta ou conflito com o movimento trabalhador masculino, que via nas mulheres a concorrência. As mulheres eram permanentemente discriminadas, quer pelas atividades restritas que estavam autorizadas a desempenhar, quer pela ausência de salário ou salário simbólico a que estavam condenadas. Com efeito, podemos afirmar que as mulheres se inseriram no mercado de trabalho como sendo não-remuneradas pelo mesmo, e essa inserção teve o seu primeiro auge com a Primeira Guerra Mundial, quando as mulheres "foram obrigadas a substituir nas fábricas os postos vacantes dos homens recrutados pelo serviço militar." (SCHOLZ, 1996, p. 27). Apesar disso, as mulheres foram as mais atingidas pelo desemprego, com a primeira crise econômica mundial.

No pós-Segunda Guerra Mundial, a relação entre os sexos passa por nova transformação, já que a entrada das mulheres no mundo do trabalho remunerado obriga a repensar a lógica tradicional da divisão dos sexos, assim como a questão do gênero, isto é, a questão da repartição de papéis socialmente impostos e construídos. A progressiva equiparação entre homens e mulheres, nomeadamente, o fato de as mulheres serem cada vez mais instruídas, colmatando o abismo formal e visível entre uns e outros, escancara as assimetrias das relações de poder entre os sexos. Ao mesmo tempo em que as mulheres se tornam "iguais", no nível da formação e acesso, permanecem "desiguais", no que diz respeito ao reconhecimento salarial, tipo de trabalho e gestão das tarefas domésticas. A isso se deve acrescentar a transmutação da própria família moderna burguesa, já que se passa a questionar a necessidade desse modelo e se abrem agora possibilidades de redefinição, quer da instituição da família, 
quer do domínio dos afetos e seu impacto na construção da subjetividade. Ressalta Scholz (1996, p. 29):

Quanto mais coisificadas as relaçoes humanas se apresentam, e portanto quanto mais desenvolvida for a relação de valor patriarcal e a-subjetiva, mais nítidas despontam as cisões patriarcais, que hoje já não se alinham com a mesma evidência de antes, ao relacionamento homem-mulher. Tais cisōes, além de problemas individuais, tornam-se também uma questão pública, isto é, política. Sobretudo os "novos movimentos sociais", que subiram ao palco social nos anos 70 e 80 compreendem a si mesmos como reação ao carácter anónimo e abstrato das relaçōes sociais. Se atentarmos no leque de temas ao redor dos quais se agrupam tais movimentos, saltará aos olhos a espantosa correspondência que eles guardam com as atribuiçóes patriarcais referentes "à mulher".

Com efeito, no seguimento dessa passagem, compreendemos que a questão da mulher sempre foi o locus de resistência à lógica do capital assente na categoria do trabalho abstrato. $\mathrm{O}$ trabalho doméstico, o qual, maioritariamente, é pensado como oposto ao trabalho abstrato, torna-se o espaço no qual a possibilidade de rebeldia se concretiza e a partir do qual a emancipação se afirma como ideal regulador de novas práticas (por exemplo, movimentos pacifistas, ecológicos etc.). Os novos movimentos se alinham e se desenham dentro de uma lógica "feminina", e não de uma lógica trabalhista masculina. Isso sugere algo importante, a saber, que na desconstrução do ideal da razão, tal como conduzida pela teoria crítica de Adorno e Horkheimer, culminando na sociedade industrial e na sociedade do espetáculo de filósofos como Guy Debord, surgem espaços de subversão conduzidos ou orientados pela questão das mulheres. Em outras palavras, a denúncia dos paradoxos trazidos pelo capitalismo num ambiente democrático adquire potencial prático e transformador, na medida em que as mulheres são as agentes que exemplificam e encarnam esses paradoxos e, ao mesmo tempo, tomando para si a tarefa de redefinição da questão do gênero, conduzem o processo pragmático da desconstrução do patriarcado. Essa desconstrução é a condição necessária (mesmo que não suficiente) da superação do capitalismo e da realização de uma sociedade efetivamente mais democrática. A questão da mulher não é hoje apenas uma questão secundária e hierarquicamente inferior ou menos importante do que a questão de classe; pelo contrário, a questão da mulher expôe em todo o seu vigor a ferida que o patriarcado perpetrou no processo de consolidação das sociedades capitalistas. 
Nesse sentido, posiciono-me de forma distinta de Scholz. Para a autora, a dicotomia privado/público, feminino/masculino constitui uma relação de interdependência necessária entre mulheres e homens; a desigualdade supóe um tipo de igualdade por princípio, uma vez que, sem as mulheres, os homens não conseguem cumprir a sua função instrumental do sistema capitalista. Porém, essa interdependência não pode ser vista como supondo qualquer tipo de reciprocidade. Só há reciprocidade entre iguais; se homens e mulheres são, desde o ponto de partida conceitual e prático, definidos como desiguais, só é possível conceber essa interdependência como explicitação da assimetria de relaçôes de poder e a progressiva afirmação de uma lógica de dominação, isto é, do patriarcado: o homem representa o universal, o abstrato, a razão, enquanto a mulher representa o singular, o concreto, o intuitivo e o irracional.

\section{INCORPORANDO A MULHER? O PAPEL DA CRÍTICA NA REINVENÇÁO DA ESQUERDA (FEMINISTA)}

Neste momento, quero defender que a universalização do "trabalho abstrato" e sua extensão às mulheres nos obriga hoje a desenvolver uma crítica acerca da "questão da mulher" e seu papel na superação ou transformação do patriarcado. Essa crítica parte de três deslocamentos importantes: 1. O deslocamento da lógica de conflito de classes para a lógica do gênero; 2 . O deslocamento da razão abstrata instrumental para uma razão sensivel; 3. O deslocamento de uma esquerda "abstrata" e ossificada para uma esquerda feminista, consciente da dupla cisão estrutural e pessoal constitutiva de todas as relaçóes sociais. A partir de tal crítica, é possível não só transformar o esquema conceitual através do qual se analisa e se atribui, projetando, um sentido à realidade, como também transformar as práticas (reguladas pelo fetichismo da mercadoria), subvertendo as suas intençôes originais.

\section{PRIMEIRO DESLOCAMENTO}

Comecemos pelo primeiro deslocamento, da lógica de conflito de classes para a lógica de gênero. Afirmei acima que a leitura feita por Marx e Engels acerca do papel atribuído à mulher se define pela adoção de um determinismo natural (visível na divisão sexual) que se transmuta num determinismo econômico, ou seja, "a origem da opressáo de mulheres e crianças por homens é baseada apenas no controle da propriedade privada." (BROWN, 2012, p.54). 
Essa leitura preliminar sugere que, uma vez abolida a propriedade privada, seria superada a lógica da opressão dos homens sobre as mulheres. Porém, como Brown sublinha enfaticamente, esse argumento é problemático (inclusive dentro do esquema conceitual proposto pelos autores) por duas razóes: em primeiro lugar, embora a dependência econômica seja um fator crucial para compreender a posição das mulheres na sociedade, esse não é o único fator. É possível conceber uma sociedade sem propriedade privada, isto é, onde uma das premissas essenciais do capitalismo é superada, sem que essa superaçáo se traduza na superação da lógica de opressão e dominação. Em segundo lugar, Marx e Engels reconhecem que a superação da propriedade privada não implica uma transformação mais radical na definição dos papéis desempenhados por homens e mulheres, ou seja, a mulher, mesmo náo dependente economicamente do homem ou marido, poderia permanecer na esfera privada, da "casa”, e desempenhar as suas "funçôes". Ora, essas funçôes através das quais a mulher é definida são produto de dominaçáo e simultaneamente meio para perpetuação dessa dominação. Brown enfatiza que "[o] lar pode ser um santuário para os homens, em primeiro lugar por causa da opressão geral das mulheres." (BROWN, 2012, p.55). Se a opressão do gênero existe antes do capitalismo, não é possível superar a lógica da desigualdade e da opressão por meio da mera superação do modo de produção capitalista. Uma sociedade emancipada não é uma sociedade náo-capitalista, contudo, antes, uma sociedade que supera e transcende todas as formas de opressão. A opressão do gênero é a primeira e mais fundamental condição de possibilidade de todas as outras, já que inaugura as dicotomias que definem o nosso a priori histórico, como, por exemplo, privado/público, feminino/masculino, passivo/ativo, concreto/ abstrato, entre outras.

Isso sugere que o foco da nossa atenção não se deve restringir à categoria de "classe" nem ao movimento perpétuo de luta de classes que tem moldado a história até hoje; essa luta de classes supóe uma luta anterior, primária, subjacente a toda a organização social, econômica, familiar e cultural. É irónico pensar que a mesma "classe" que transformou as relaçóes feudais e reconfigurou as relações sociais na esfera doméstica e internacional (através do comércio), com aparente intenção progressista, foi vítima de um processo de regressão pelo reforço e postulação da diferença entre gêneros. Essa regressão, indissociável de estratégias repressivas e opressivas, passa a definir-se numa rede conceitual capitalista que, em última análise, manifesta a sua natureza contraditória: 
O capitalismo não só cria crises porque "há demasiada civilização, demasiados bens, demasiada indústria, demasiado comércio”, como também cria novas forças subjetivas que eventualmente irão superar o sistema: as armas usadas pela burguesia para derrubar o feudalismo se voltam agora contra a própria burguesia. (BROWN, 2012, p.54).

A burguesia produz os instrumentos humanos que irão derrubar a sua ordem: os trabalhadores modernos, os proletários. Porém, essa criação (e repito, assente na divisão entre os sexos) só é possível porque as mulheres (invisíveis e igualmente exploradas) o propiciam. Por outras palavras, há duas situaçôes distintas que se cruzam e complementam, apontando para um resultado comum: por um lado, as mulheres ficam "em casa", permitindo que o seu trabalho (não pago) apoie o trabalho remunerado do homem; por outro lado, as mulheres (e crianças) também são forçadas a entrar no mercado de trabalho, embora a remuneração seja bastante inferior. ${ }^{6}$ Ao fazê-lo, as mulheres passam a desempenhar outros papéis que vão contestar a representação dominante da "família patriarcal”, onde o pai de família exerce controle absoluto sobre os seus membros. $\mathrm{O}$ capitalismo entra assim na esfera privada e cria condiçốes para a contestação das relaçóes de poder do homem sobre a mulher e sobre as crianças.

Embora Marx tenha subestimado o potencial das mulheres na transformação do sistema capitalista, obviamente, o papel dual das mulheres, explícito na cisão privado/público, cria condiçóes fundamentais para a subversão da instituição da família. Isso sugere a importância de fazer esse deslocamento para uma lógica de gênero, no sentido de considerar as tensôes e contradições, nas formas como os papéis sociais são determinados, definidos, justificados e, em última análise, legitimados. A questão do gênero se torna a questão primordial, a partir da qual devemos criar espaços efetivos de transformação crítica e social.

\section{SEGUNDO DESLOCAMENTO}

Abordemos agora o segundo deslocamento: o deslocamento da razão abstrata instrumental para uma razão sensivel. Desde a teoria crítica que está

\footnotetext{
${ }^{6}$ As mulheres podem ser vistas como trabalhadoras distintas dos homens, na medida em que o seu trabalho é diferente. Trabalho de casa e o cuidado com as crianças são formas de trabalho necessárias, todavia, como não são produtoras de mercadorias, são subestimadas do ponto de vista do capitalismo. Embora o trabalho "de casa" não produza valor de troca per se, mas apenas valor de uso, ele é essencial para a produção da mais-valia. Ver Margaret Benston, no seu artigo seminal "The Political economy of Women's Liberation”, em Monthly Review, 1969.
} 
definido um horizonte de recusa ou resistência aos ideais iluministas assentes na ideia de uma razão universal, traduzida objetivamente na produção de discursos (de direitos, por exemplo), instituiçôes (Estado, sociedade civil, família) e subjetividades (o sujeito racional "neutro", assexuado). É impossível ignorar a relação entre iluminismo e capitalismo, já que, como Marx e Engels bem notaram, em $A$ ideologia alemã, os ideais dominantes de uma época são sempre os ideais da classe dominante (e dominadora). O que significaria romper com essa razão abstrata instrumental e instrumentalizada?

Em primeiro lugar, recusar as categorias a partir das quais cada sujeito se define. Entretanto, como fazer essa recusa? É preciso nos redefinirmos, não como "subjetividades" em abstrato, mas como seres que estáo sempre em relação. "Gênero é uma propriedade extrínseca ou relacional de indivíduos, e as relaçóes em questão são sociais.” (HASLANGER, 2012, p. 41). Isso significa que a contestação da razão instrumental começa pelo trabalho genealógico e fenomenológico, num sentido quase existencialista, de questionar a justificação dada para papéis atribuídos, definidos e impostos pela sociedade. Os ideais ganham a sua força prescritiva apenas se conseguirem impor ou convencer-nos acerca da sua correção e importância na administração dos papéis sociais. Por outras palavras, o ideal (nesse caso, de "racional", de "homem", de "mulher" etc.) não é capaz de fornecer a sua própria justificação; isso significa que devemos recusar qualquer discurso essencialista que defina "homens" ou "mulheres", pois, ao não o fazer, estaríamos prescindindo da componente crítica necessária a qualquer transformação. Uma razão sensivel é uma razão que se questiona e critica a si mesma; uma razão que não se constrói em função da sua separação com o seu outro, mas que se define na plena consciência de que ela é contraditória, múltipla, e se manifesta de formas tensas, incompletas e muitas vezes de formas aparentemente irresolúveis. Uma razão sensível é uma razão material, concreta, física, a qual se redefine permanentemente, pois ela é, acima de tudo, o horizonte entendido enquanto condição de possibilidade para qualquer relação. Por isso, ela é também uma razão relacional, histórica, contextual, reflexo da sua realidade específica, porém que, pelo seu potencial crítico, se propóe simultaneamente modificar-se. Uma razão certamente dialética, capaz de lidar com as suas tensôes, sem aspirar a uma superação total e absoluta ou, por outras palavras, abstrata.

\section{TERCEIRO DESLOCAMENTO}


O terceiro deslocamento consiste na passagem de uma esquerda "abstrata" e ossificada para uma esquerda feminista, consciente da dupla cisão estrutural e pessoal constitutiva de todas as relaçóes sociais. Podemos asseverar que há um consenso na afirmação de que a esquerda, independentemente da maneira que a queiramos definir, aceita a coordenada central da "igualdade" como premissa da qual todas as outras derivam. Há várias esquerdas, umas mais socialistas, outras mais de "centro"; não entraremos aqui no debate ideológico das diferentes ramificaçóes. $\mathrm{O}$ que podemos afirmar é que parte da esquerda se constrói, ainda, sobre um discurso marxista geralmente associado a uma crítica do capitalismo, por um lado, e uma crítica do patriarcado, por outro. Com a crítica do capitalismo, espera-se conseguir expor e denunciar a lógica de exploração nas relaçôes de trabalho (e aí a categoria de "classe" é ainda dominante), enquanto, com a crítica do patriarcado, se denuncia a desigualdade no tratamento do gênero. Essa desigualdade, por sua vez, tem origens ideológicas, as quais podem ser vistas como estruturais, necessariamente ligadas às condições materiais, como Marx o faz, ou como relativamente independentes dessas condiçóes, como, por exemplo, defende Hartmann (1981).

Teria que entrar aqui nas crises mais recentes que a esquerda tem confrontado, sobretudo desde a desintegração da União Soviética e a ascensão e consolidação do modelo neoliberal, que confronta na sua base o modelo democrático de bem-estar social. Há um relativo consenso no reconhecimento de que a esquerda precisa se reinventar. Esse impasse pode ser lido de acordo com a histórico específico de cada país - a dinâmica da esquerda é diferente no Brasil, em Portugal, na Espanha, na França, entre muitos outros. Independentemente das variáveis específicas, há algo de comum, e esse algo é o fato de a esquerda estar ainda dominada por um conjunto de categorias (inclusive marxistas) que parecem não ter mais lugar nas práticas contemporâneas. Isso sugere duas coisas: do ponto de vista do patriarcado, é óbvio que teorias do patriarcado (i.e., teorias que denunciam a lógica de opressão e dominação, nesse modo de construçáo do mundo e das relaçóes sociais) não conduzem necessariamente a uma liberação, emancipação ou redefinição real das mulheres e seu papel. Do ponto de vista feminista, isso obriga a uma reformulação da agenda que visa a uma emancipação, tomando em consideração as condiçóes atuais em que vivemos, isto é, moldados por uma ideologia neoliberal que pouco ou nada tem a ver com a própria ideologia marxista. Assim, quando afirmo que é preciso abandonar a esquerda ossificada e abstrata, quero sublinhar a ideia central de que a esquerda só conseguirá sobreviver, se tomar a questáo do gênero como o seu centro de análise (o que supóe os deslocamentos anteriores). 
Isso implica desconstruir as variaçóes feministas que estão em "luta" por se tornarem a narrativa dominante (e que espelham apenas aquilo que o modelo neoliberal impóe, i.e., a fragmentação de sorte a que uma ação concertada se torne impossível) e partir de um ponto comum, nomeadamente, a crítica à instituição da família, porque esta é o espaço privilegiado onde se definem os papéis sociais (e o gênero). Conforme Sharon Smith (2015),

o entendimento do papel da família é fundamental para compreender a cidadania de segunda classe das mulheres na sociedade, respondendo a perguntas básicas: [...] Porque as mulheres são relegadas ao papel de objetos sexuais, sujeita à aprovação ou desaprovação dos homens? Por que as mulheres hoje ainda lutam pelo direito de controlar seus próprios corpos e vidas reprodutivas? Iniciou-se com a família, mas as repercussóes se estendem muito além da vida dentro da família.

A luta feminista hoje, isto é, uma luta concertada, articulada e aceite como ponto de partida para toda a crítica social, deve ser pensada como transversal aos vários "feminismos" e concentrar-se na busca de condiçôes efetivas de transformação e superação de uma lógica de opressão e dominação. Essa superação começa pela desconstrução da imagem naturalizada da "família patriarcal" como unidade fundadora da sociedade. Vejamos este depoimento de Bodin, escrito em 1576, nos Seis livros sobre a República:

A partir do momento em que o casamento é consumado a mulher é sujeita ao seu marido [...] em todos os sistemas legais o marido é visto como mestre das açóes da sua mulher, e intitulado a usufruir de toda a propriedade que ela possa ter, enquanto que a mulher não pode sequer vir aos tribunais quer como acusadora, quer como defesa, sem o consentimento do seu marido [...] O poder, autoridade e comando que um marido tem sobre a sua mulher é permitido quer pela lei divina quer pela lei positiva, para ser honrado e correto. [...] A autoridade pertence àqueles que reconhecem o poder de comandar outro. (BODIN, 2009, p. 51-52).

Nessa passagem, vemos como a autoridade se constrói a partir do reconhecimento da lei natural e divina, a qual impóe, como sua contraparte, o dever de obediência. Bodin reproduz apenas uma tradição consolidada (discursivamente) desde o Antigo Testamento. O patriarca tem total poder sobre a vida e a morte dos seus filhos, escravos e mulher. Essa família patriarcal nada mais é do que um conjunto de relaçóes servis, assimétricas, desiguais. Se buscamos conquistar (ou melhor, construir) uma igualdade 
efetiva, mesmo que esta seja entendida preliminarmente como horizonte simbólico de produção e reprodução de sentidos e práticas sociais, devemos começar pela transformação do conceito e práticas de família, pois, com ela, toda a organização social será também transformada. Esta é a condição sine qua non para reciprocidade, reconhecimento e superação da lógica de dominação.

COSTA, M. N. Transforming the patriarchy? The role of the feminist struggle in the reconfiguration of Marxist categories. Trans/formlaçāo, Marília, v. 41, n. 3, p. 125-144, Jul./Set., 2018.

\begin{abstract}
Based on an analysis of Marxist categories, I attempt in this article to bring into the domain of visibility the 'issue of women', and argue that it must be the guiding thread in the process of identification (or invention) of conditions of possibility for the transformation of the system of practices (and discourses) that aim at human emancipation, understood as overcoming the logic of domination.
\end{abstract}

KeYwords: Patriarchy. Capitalism. Feminism. Left. Gender.

\title{
REFERÊNCIAS
}

BENSTON, M. The political economy of women's liberation. Monthly Review, v. 21, n. 4, p. 13-27, 1969.

BODIN, J. Six books of the commonwealth. Tradução de M. J. Tooley. USA: Seven Treasures, 2009.

BROWN, H. Marx on gender and family: a critical study. Leiden/Boston: Brill, 2012.

DI STEFANO, C. Configurations of masculinity: a feminist perspective on modern political theory. Ithaca: Cornell University Press, 1991.

GERMAN, L. Theories of patriarchy. International Socialism, v. 2, n.12, Spring 1981.

HARTMANN, H. The family as the locus of gender, class and political struggle: the example of Housework. Signs, v. 6, n. 3, p. 366-394, 1981.

HASLANGER, S. Resisting reality: social construction and social critique. Oxford: Oxford University Press, 2012.

HARVEY, D. The enigma of capital and the crises of capitalism. Londres: Profile Books, 2011

HOLSTROM, N. A marxist theory of women's nature. Ethics, v. 94, n. 3, p. 456-473, 1984. 
MARX, K. Manifesto comunista. Tradução de Álvaro Pina. São Paulo: Boitempo, 2005. . Manuscritos econômico-filosóficos. Tradução de Jesus Ranieri. São Paulo:

Boitempo, 2008.

. O capital. Livro I. Tradução de Rubens Enderle. São Paulo: Boitempo, 2015.

MARX, K.; ENGELS, F. A ideologia alemã. Tradução de Luis Cláudio de Castro e Costa. São Paulo: Martins Fontes, 2001.

MIES, M. Patriarchy and accumulation on a world scale: women in the international division of labor. Londres: Zed, 1998.

SCHOLZ, R. O valor é o homem. Tradução de José Marcos Macedo. Novos Estudos CEBRAP, n. 45, p. 15-36, jul. 1996.

SMITH, S. Marxismo, feminismo e a libertação da mulher. 2015. Disponível em: <https://feminismosemdemagogia.wordpress.com/2015/05/24/marxismo-feminismo-e-alibertacao-da-mulher-por-sharon-smith/>. Acesso em: 31 maio 2016.

Recebido: 2016-07-08

Aceito: 2017-03-14 